\title{
A demonstration-scale evaluation of GAC as biologically removing TOC from drinking water in Alabama
}

\author{
A. Nabors, J. Heberling, P. Barron \& J. Shotts \\ Department of Engineering, Birmingham Water Works Board, USA
}

\begin{abstract}
Granular activated carbon (GAC) media for filtration of drinking water can be used to remove microscopic substances at extremely effective rates though a process of adsorption. Two major problems with GAC are the high start-up costs and the short effective removal timeline before GAC replacement or reactivation. Three years ago, the Birmingham Water Works Board (BWWB), undertook a project sponsored by the Water Research Foundation (WRF) to evaluate GAC for removal of organics, pharmaceuticals, and pesticides. These results were published in December 2010. A primary coagulant change at the plant occurred shortly after the initial study and a spin-off study commenced. The GAC filters are continuously monitored for any significant changes in performance. Grab samples including total organic carbon (TOC), heterotrophic plate counts, and nitrates are collected and sent for analysis. Initial results show there is still significant reduction in TOC through the filters. This is important because previous research suggests the media has an adsorption timeline of approximately six months after which GAC media was determined to be biologically active. If GAC is effective at removing organics several years after installation through biofiltration which doesn't require reactivation, it may be a cost effective alternative to current procedures enabling BWWB to meet future regulations on drinking water.

Keywords: granular activated carbon, total organic carbon, drinking water, organics removal, filtration media, ferric sulfate, disinfection by-products.
\end{abstract}




\section{Introduction}

Federal law, mandated by the United States Environmental Protection Agency (USEPA), along with additional state law, outlines very specific requirements for finished drinking water [1]. These requirements continue to become more stringent with the rapid advancement of technology and our ever-expanding ability to monitor and analyze micropollutants. Previous research shows that granular activated carbon (GAC) media can be used in conjunction with sand, per dual media filtration, to successfully remove emerging compounds at extremely small, part per trillion (ppt), concentrations through adsorption and/or biofiltration [2-8]. However, for this particular study, after approximately six months the GAC was not as effective at removing the micropollutants as it was originally but there was still some notable biological filtration occurring [2]. Since the cost of GAC is extremely high it was determined that the adsorption benefits for micropollutants did not outweigh the cost.

Soon after the original study commenced and a major chemical change at the filter plant, a spin-off study began. This study will take a look into the differences in filter performance after the coagulant was changed from aluminium sulfate (alum) to ferric sulfate (ferric). Beginning January 2012, the Stage 2 Disinfection By-product Rule (DBPR) will mandate stringent regulations as to the amount of DBPs that will be present in finished drinking water [9]. Research suggests that reduced total organic carbon (TOC), a subset of natural organic matter, will produce less DBPs in the distribution system [8,10-17]. If the biological GAC, or GAC post-adsorption, can further decrease the amount of TOC that is present in finished drinking water then GAC may prove to be a costeffective option after all.

\subsection{Project scope}

The scope of the study is to evaluate how effective the GAC media is at removing TOC in biological mode after the coagulant changeover occurred. Secondly, an evaluation of the amount of TOC that is removed compared to the differing media depth of individual filters will determine if additional TOC removal should be expected with a deeper bed.

\subsection{Project description}

Four demonstration size filters were built with the same parameters such as dimensions, filtration rates, backwash rates, and monitoring instrumentation with the exception of the media depth. Filters D1, D2, and D4 had thirty two inches of GAC. D3 had forty two inches of GAC so that a comparison of the bed depth to removal could be determined.

\subsection{BWWB background}

The BWWB is located in the south eastern United States in the state of Alabama. The company owns and operates four surface water treatment plants that are 
spread throughout the Birmingham Metropolitan area. These four plants are rated to treat a combined 190 million gallons a day and serve approximately 600,000 customers across five counties. Shades Mountain Filter Plant (SMFP) is the focus of this study.

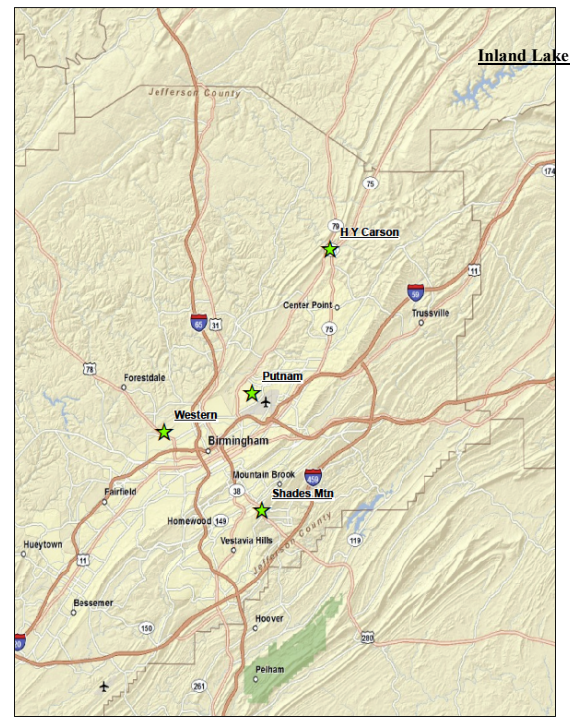

Figure 1: Map of the BWWB Surface Water Drinking Plants and Inland Lake. (Provided by BWWB.)

\section{Methods and materials}

\subsection{Shades mountain filter plant description}

SMFP is the largest and oldest plant in the BWWB system and produces about $50 \%$ of the systems demand. SMFP's raw water has high alkalinity, $>80 \mathrm{mg} / \mathrm{L}$; moderate TOC, $3-8 \mathrm{mg} / \mathrm{L}$; a $\mathrm{pH}$ of $7-8$; and a wide range of turbidity due to flashing from rain events, 4 - $200 \mathrm{ntu}$.

SMFP receives its raw water from Lake Purdy and the Cahaba River which can create a complicated blend for treatment (see Fig. 2). Lake Purdy is high in alkalinity, low in turbidity, and high in TOC. Like most rivers, the Cahaba River is susceptible to rain events that cause spikes in the turbidity and TOC. Since raw water can come from either source individually or from a blend of both, it is important to monitor what effect raw water quality may be having on the treatment process. 


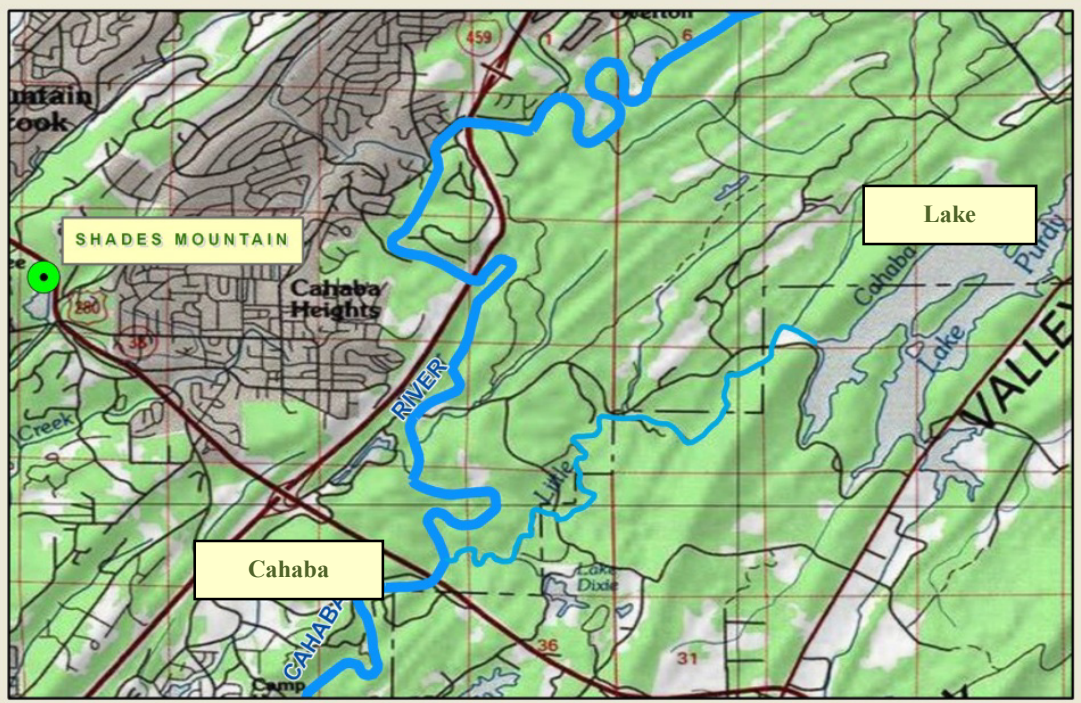

Figure 2: $\quad$ Map of SMFP and its source waters. (Provided by BWWB.)

\subsection{GAC demonstration description}

The GAC Demonstration (GAC Demo) was built in-between the basin for the raw water and the settled water basin. It receives water that has been chemically treated or coagulated, flocculated and then settled by gravity. This water is known as settled water. Once water is filtered, it is recycled back to the raw water basin alleviating concerns about sending this water into the distribution

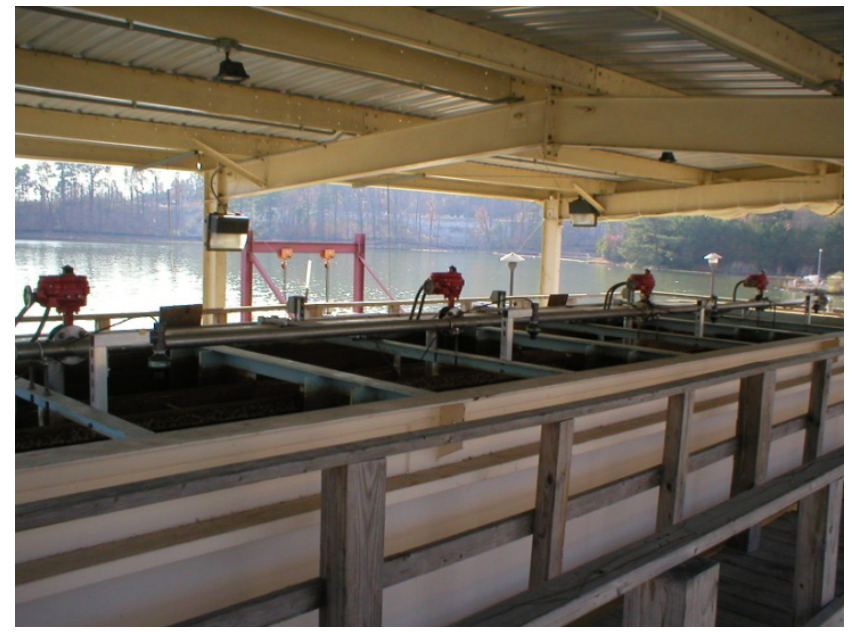

Figure 3: $\quad$ Top of the GAC filters. (Provided by BWWB.) 
system. The filters are labelled D1, D2, D3, and D4. They are each dual media filters with twelve inches of sand and thirty two inches of GAC, with the exception of D3 that has forty two inches of GAC.

\subsection{Sample procedures}

Samples were pulled from the influent water, also known as SMFP settled water, to the GAC Demo as well as each individual filter from April 2009 through October 2010 following the coagulant change from alum to ferric. This nineteen month period includes data from two separate summers. This is important because summer is typically the high season for DBP formation in the distribution system [10]. All samples were taken to Envirolab, an EPA certified BWWB lab, and analyzed within the allotted time per Standard Method 5310-C [18].

\section{Results and discussion}

A previous study of the same facility, performed in collaboration with BWWB and the Water Research Foundation and others, determined that all four GAC filters were in adsorption removal mode for the first six months of treatment with alum [2]. This study lasted just under one year and included six months of adsorption data followed by almost six months of biofiltration data with alum as the coagulant. Data with ferric as the coagulant began after the first year and lasted nineteen months. For purposes of this evaluation only data from filters D2 and D3 will be used, noting that the only difference between the two is that the bed depth of D3 is greater. In an attempt to normalize the data, it is common practice to express TOC removal measured as a percentage of the incoming TOC value (see Figure 4).

\begin{tabular}{|c|c|c|}
\hline & \multicolumn{1}{c}{ D2 } & D3 \\
\hline Avg. Alum/Adsorption & $35 \%$ & $44 \%$ \\
\hline Avg. Alum/Biofiltration & $15 \%$ & $15 \%$ \\
\hline Avg. Ferric/Biofiltration & $13 \%$ & $16 \%$ \\
\hline
\end{tabular}

Figure 4: $\quad$ Averages based on chemical types and filtration mode.

This data shows that there is a significant difference in the adsorption and biofiltration modes regardless of the coagulant that is being used to chemically treat the water. It also suggests that there isn't any additional TOC removal when comparing ferric treated water to alum treated water. When bed depth and adsorption are considered, there is almost a $10 \%$ improvement with the additional 10 inches of GAC that are in D3 compared to no notable difference between alum and biofiltration and only a slight improvement between ferric and biofiltration. However, a further look into the exact values of the TOC depicts a slightly different outcome (see Fig. 5). 


\begin{tabular}{|c|c|c|c|}
\hline & Influent & \multicolumn{1}{c}{ D2 } & D3 \\
\hline Avg. Alum (ppm) & 2.21 & 1.73 & 1.5 \\
\hline Avg. Ferric (ppm) & 1.81 & 1.56 & 1.51 \\
\hline \% Difference & $18 \%$ & $10 \%$ & $1 \%$ \\
\hline
\end{tabular}

Figure 5: Average actual TOC values and the percent difference between them.

The influent TOC values for alum are 18\% higher than that of ferric. This means that the actual TOC removal amount (in ppm) during filtration is indeed higher during treatment with alum than treatment with ferric. There is also a slight variation, about $10 \%$, between the regular and deeper bed depth with alum that is not realized with ferric treated water. This means that with alum treatment, the filters are needed to remove additional TOC that is not present to be removed during ferric treatment. It is interesting to note that the final actual TOC values from the deepest filter are within $1 \%$ of each other suggesting that the overall outcome of alum and GAC biofiltration is equal to that of ferric and GAC biofiltration.

\section{Conclusion}

Results from the study show there is not a statistically significant difference between biofiltration with ferric treated water and biofiltration of alum treated water. There is a slight improvement of alum treated water after filtration with GAC in biofiltration or adsorption mode and bed depth however this did not hold true with ferric treated water. Further analysis as to the type of TOC that is being removed by each individual chemical as well as filtration mode could help to further explain this result.

\section{Reference}

[1] United States Environmental Protection Agency (USEPA), Current Drinking Water Regulations. Office of Water Website, Washington DC, EPA. http://water.epa.gov/lawsregs/rulesregs/sdwa/currentregulations.cfm.

[2] Chowdhury, Z., et al., Cost Effective Regulatory Compliance with GAC Biofilters. Water Research Foundation, Denver, CO, 2010.

[3] Camper, A., LeChevallier, M., Broadway, S., \& McFeters, G., Bacteria Associated with Granular Activated Carbon Particles in Drinking Water. Applied and Environmental Microbiology, 52(3), pp. 434-438, 1986.

[4] Wu, H. \& Xie, Y., Effects of EBCT and Water Temperature on HAA Removal using BAC. Journal AWWA, 97:11, pp. 94-101, 2005.

[5] Zhu, I., Getting, T., \& Bruce, D., Review of biologically active filters in water applications. Journal AWWA, 102:12, pp. 67-77, 2010.

[6] Myers, T. \& Scharf, R., GAC Treatment: A Versatile Technology Stands the Test of Time. AWWA Opflow, pp. 10-13, January 2011. 
[7] Evans, P., Nature Works Biological Treatment Methods Yield High-Quality Water. AWWA Opflow, pp. 12-15, July 2010.

[8] Emelko, M., Huck, P., Coffey, B. \& Smith, E. F., Effects of media, backwash, and temperature on full-scale biological filtration. Journal $A W W A$, 98:12, pp. 61-73, 2006.

[9] USEPA, Proposed Stage 2 Disinfectants \& Disinfection By-products Rule. Office of Water Website, Washington DC, EPA 815-F-03-006. http://www.epa.gov/safewater.

[10] Cochran, J., Barron, P., Cox, W., Nabors, A., Core, I., \& Roberson, D., Coagulant Changeover: Overcoming the Trials and Tribulations. Proc. Of the 2009 AWWA Water Quality and Technology Conf. Seattle: Washington, 2009.

[11] Cochran, J, Barron, P, \& Nabors, A., Evaluating Changing the Primary Coagulant for a Drinking Water Filter Plant through the use of a Mobile Pilot Plant and Determining the Correct Changeover Protocol. Proc of the 2010 AIChE Spring Meeting \& $6^{\text {th }}$ Global Congress on Process Safety. San Antonio: Texas, 2010.

[12] Archer, A.D. \& Singer, P.C., An Evaluation of the relationship between SUVA and NOM coagulation using the ICR database. Journal $A W W A$, 98:10, pp. 110-126, 2006.

[13] Krasner, S.W., Westerhoff, P., Chen, B., Rittmann, B.E., Nam, S., \& Amy, G., Impact of Wastewater Treatment Processes on Organic Carbon, Organic Nitrogen, and DBP Precursors in Effluent Organic Matter. Environmental Science \& Technology, 10:1021, 2009.

[14] Volk, C.J. \& Lechevallier, M.W., Effects of Conventional Treatment on AOC and BDOC levels. Journal AWWA, 94:6, pp. 112-123, 2002.

[15] Roy, A.J., Treatment alternatives for compliance with the Stage 2 D/DBPR: An economic update. Journal AWWA, 102:3, pp. 44-51, 2010.

[16] Oneby, M., Reid, A., \& Mahmutoglu, S., Model Sheds Light on TTHM Formation. Journal AWWA, 101:11, pp. 20-23, 2009.

[17] Nabors, A., Barron, P, \& Cox, W., An Evaluation of the Role of Coagulation on TOC and DBP Formation in Drinking Water. Proc of the 2011 AEHS International Conference on Soil, Water, Energy and Air. San Diego: California, 2011.

[18] American Public Health Association (APHA), American Water Works Association, \& Water Environment Federation, Standard Methods for the Examination of Water and Wastewater, $21^{\text {st }}$ Ed. APHA: Washington D.C., Section 5310-C, pp. 5-19-5-25, 2005. 